\title{
Characteristics and formation analysis of mudstone in the Shahejie Formation, Dongpu Sag
}

\author{
XIANG ZENG ${ }^{1}$, LUYAO ZHANG ${ }^{1}$, YANFENG $\mathrm{LI}^{1}$, AND \\ JINGONG CAI ${ }^{1 *}$ \\ ${ }^{1}$ State Key Laboratory of Marine Geology, Tongji University, \\ Shanghai 200092, China ( "correspondence: \\ jgcai@tongji.edu.cn )
}

Mudrock is composed of minerals and organic matter. The origin and preservation of organic matter are controlling factors of the hydrocarbon generation and evolution of lacustrine mudrock. Thus it is a key method for the source rock research to study the deposition process from the view of the organic matter and sedimentary environment. Following this idea, we try to find out the reasons for the great difference in hydrocarbon generation between the northern and southern part of Dongpu Sag. In this paper, we sample the lacustrine rocks of the Shahejie Formation in Dongpu Sag to analyze their lithofacies characteristic and then look for the reasons mentioned above. Based on analysis results, the mudrocks in study area are divided into three lithofacies: the silt-rich massive mudstone is rich in exogenous components and comprises organic matter from destructed microbial mats; the homogeneous massive mudstone mainly composes clay minerals and organic matter fragments; the laminated mudstone features more authigenic minerals and amorphous organic matter. The hydrocarbon generation ability of these three lithofacies increases in sequence. According to further research, it is the environment factor that causes the differences in $\mathrm{OM}$ characteristic and hydrocarbon generation of the mudrocks. The silt-rich massive mudstone, the homogeneous massive mudstone and the laminated shale are sequently deposited in sedimentary environments of increasing depth, water salinity and reducing condition. The correlation analysis between sedimentary environment and organic matter confirms that the environment factor controls the accumulation and preservation of organic matter, which causes the great differences in hydrocarbon generation ability of the three lithofacies. Comparing the northern and southern part of study area in lithofacies, it can be found that the content of laminated mudstone which owns greater hydrocarbon generation ability is much higher in the northern part, leading to higher hydrocarbon production over the southern part. In conclusion, the sedimentary environment and organic matter composition will greatly affect the hydrocarbon genertion ability of mudrocks. 